\title{
Uso de Recibos de Ações nos Estados Unidos (ADRs) para Arbitragem
}

\author{
André Machado Caldeira ${ }^{1}$, Reinaldo Castro Souza ${ }^{2}$, Maria Augusta Soares Machado ${ }^{3}$ \\ 1,2, Pontifícia Universidade Católica do Rio de Janeiro, Rua Marques de São Vicente, \\ 225 - Gávea, Rio de Janeiro, RJ. \\ ${ }^{3,}$ Faculdades IBMEC-RJ, Av. Pres. Wilson, 118 - Centro, Rio de Janeiro, RJ. \\ ${ }^{1}$ amcaldeira@yahoo.com.br ; ${ }^{2}$ reinaldo@ele.puc-rio.br; ${ }^{3}$ mmachado@ibmecri.br
}

\begin{abstract}
Resumo
A eficiência de mercado é muito questionada por especialistas, alguns trabalhos sugerem oportunidades de arbitragem em diversas operações financeiras. Essas oportunidades podem ser explicadas principalmente pela assimetria de informação, pois a formação de preços no mercado acionário está diretamente ligada as informações, portanto o investidor que as possuir com mais rapidez, possui uma vantagem competitiva. O objetivo desse artigo é verificar a existência de oportunidades de arbitragem utilizando os Recibos de Ações nos Estados Unidos (ADRs -American Depositary Receipts), negociadas no mercado americano, e suas respectivas ações, negociadas no mercado nacional. Através do estudo de caso realizado com quatro empresas, desconsiderando os custos de transição, foram encontradas janelas de oportunidades para arbitragem. Dentre as empresas estudadas, duas apresentaram oportunidades freqüentes de arbitragem, sendo que uma delas a oportunidade de arbitragem pode ser modelada por modelo de série temporal.
\end{abstract}

Palavras Chave: Arbitragem, Eficiência de Mercado

\begin{abstract}
Specialists often question market efficiency. Some works suggest arbitrage opportunities in several financial operations. Such opportunities can be explained mainly by information asymmetry, since pricing in the stock market is directly linked to information; therefore, the investor that has access to such information the soonest has a competitive advantage. The objective of this paper is to verify the existence of arbitrage opportunities via ADRs, traded in the American market, and their respective stocks, which are traded in the domestic market. Through a case study conducted with four companies, not considering the transition costs, arbitrage opportunity windows were found. Among the companies studied, two had frequent arbitrage opportunities, for one of them the arbitrage opportunity can be shaped by the time series model.
\end{abstract}

Key-words: Arbitrage; Market efficiency.

\section{Introdução}

A carência de fontes de financiamento de longo prazo no mercado de capitais brasileiro tem levado ao aumento do número de empresas brasileiras emissoras de recibos de ações nos Estados Unidos (ADRs American Depositary Receipts), visando a obter visibilidade internacional, dar maior liquidez às negociações de seus títulos e captar recursos internacionais a taxas menores que as praticadas no mercado interno [1].

Tal aumento da quantidade de emissões de Recibos de ações nos Estados Unidos tende a tornar os mercados envolvidos mais eficientes já que aumenta a troca de informações internacionais. Mercados eficientes são benéficos à economia, e interessam tanto aos grandes investidores, pela redução dos custos de análises, quanto aos pequenos investidores, por colocálos em posição de competição favorável mediante as possíveis escolhas de investimentos, uma vez que as informações disponíveis já estão refletidas nos preços. Ao mesmo tempo, os Recibos de ações nos Estados Unidos têm lastro em ações de empresas negociados no mercado doméstico, existem possibilidades de arbitragem entre os negócios de operações com as ações emitidas no mercado de capitais nacional e os recibos emitidos no mercado externo. Por exemplo, tais oportunidades surgem em decorrência da tributação diferenciada para o investidor estrangeiro, custos de transação reduzidos, diferenças de horário de funcionamento das bolsas de valores, flutuações cambiais e diferentes padrões de transparência na divulgação de informações e de práticas de negociação [2].

Este artigo tem por objetivo analisar possibilidades de arbitragem nas operações de compra e venda de ADR, comparando os preços de ações de empresas brasileiras no mercado doméstico e os preços 
dos Recibos de ações nos Estados Unidos no mercado norte-americano. No caso presente, desconsideramos tributações, taxas de corretagens e taxas de e nos concentramos puramente nas diferenças entre as cotações.

O artigo está estruturado tendo essa seção introdutória, a segunda sessão discute alguns conceitos importantes sobre a eficiência de mercado e Recibos de ações nos Estados Unidos, tendo como seção subsequiente um estudo de caso que tem como objetivo a verificação de oportunidades de arbitragem, e por último as conclusões são apresentadas na quarta seção.

\section{Conceitos}

\subsection{Eficiencia de Mercado}

A Hipótese Eficiente de Mercado (HEM) foi a proposta por Fama em 1965 em "O comportamento de Preços de mercado de Estoque". Segundo seu trabalho de 1970 [5], um mercado é dito eficiente quando os preços refletem plenamente toda a informação disponível. Na primeira década depois de sua criação, a hipótese de eficiência de mercado transformou-se num sucesso teórico e empírico, terminando por fornecer a base teórica para muitas pesquisa na área de finanças durante os anos setenta e oitenta. Primeiramente, estas dedicaram-se à previsão de preços baseados em dados históricos; já nos anos oitenta componentes informacionais como dividendos [4] e [3] e relação lucratividade preço passaram a ser a base destas previsões [2].

O nível em que são afetados os preços, dada a informação disponível, caracteriza o tipo de eficiência desses mercados. A literatura faz uma distinção entre três níveis de eficiência [5] :

- Eficiência fraca: o preço das ações refletem plenamente a informação contida nos movimentos históricos de preços. Como movimentos do preço são totalmente independentes de movimentos históricos, é então impossível obter lucros superiores baseado no conhecimento passado.

- Eficiência Semi-forte: o mercado é eficiente no sentido semi-forte se os preços respondem instantaneamente e corretamente à informação recentemente publicada. Isto implica que não exista vantagem em analisar informação publicamente disponível, porque logo que informação torna-se pública, imediatamente é incorporada aos preços. Isto inclui lucros e anúncios de dividendo, Incorporação \& Aquisições, edições de direitos e qualquer outro tipo de informação sobre as ações da empresa.

- Eficiência forte: neste caso, os preços refletem não só a informação publicada mas também toda informação relevante, incluindo dados particulares. Nem mesmo um empregado da empresa seria capaz de obter lucros anormais devido a sua posição, porque a informação rapidamente é assimilada pelo mercado.

Estes três níveis de eficiência descansam em três suposições básicas:

- $\bullet$ os investidores são supostamente racionais. Estimam o valor presente líquido de seus fluxos de caixa utilizando sua respectivo taxa de desconto. Quando nova informação sobre a empresa torna-se pública, há uma disponível, quase imediatamente.

- Ainda que existam alguns investidores irracionais, seus negócios são casuais e, custodiante. O comprador daqui comunica ao banco que deseja efetuar a conversão e vender imediatamente o papel lá. Nos EUA, o Bank of New York é o principal custodiante de Recibos de ações nos Estados Unidos e, no Brasil, o Banco Itaú por exemplo detém grande parte das custódias. Existem três níveis de ADR, cada um com exigências crescentes de transparência e adequação às normas norteamericanas. Quando negociados over-thecounter, os Recibos de ações nos Estados Unidos não precisam seguir as normas da lei Sarbanes-Oxley portanto, não afetam os preços. Segundo a hipótese de eficiência de mercado como os passos tomados por estes investidores irracionais não são correlacionados, estes terminam por compensar-se.

- $\quad$ O terceiro argumento da hipótese de eficiência de mercado é baseado na noção de arbitragem [6], argumentando que no mercado há árbitros racionais que eliminam a influência de investidores irracionais nos preços. rápida resposta que incorpora toda a informação

Como os investidores irracionais estão comprando ações acima do seu valor justo e vendendo ações abaixo do seu valor justo, lucram menos que os investidores passivos ou árbitros. Comparado com os outros investidores do mercado estes ganham menos e, como indica Friedman 1953 [2], não podem perder dinheiro infinitamente porque passariam a ilíquidos ou, eventualmente, desapareceriam do mercado. No longo prazo, se a arbitragem não elimina a influência dos investidores irracionais nos preços do mercado, As forças do mercado o farão.

\subsection{Recibos de Depósitos nos Estados Unidos (ADRs - American Depositary Receipts)}

Para aproveitar o crescente interesse e facilitar o acesso de investidores ao capital de empresas nacionais e, dessa forma, aumentar a captação de recursos externos, as grandes companhias brasileiras utilizam como instrumento os Recibos de ações nos Estados Unidos . 
No Brasil, conforme definição do Banco Central, American Depositary Receipts são certificados representativos de ações ou outros valores mobiliários que representam direitos e ações, emitidos no exterior por instituição denominada "Depositaria", com lastro em valores mobiliários de emissão de empresas brasileiras depositados em custódia específica no Brasil. De modo genérico, ADRs são papéis emitidos e negociados no mercado de capitais dos Estados Unidos (EUA), com lastro em ações de emissão de empresa não norte-americana.

No Brasil, o Recibo de depósito nos Estados Unidos foi criado por meio da Resolução 1927, de 18 de maio de 1992, com o intuito de incentivar o mercado de ações. Dentre as empresas que lançaram esses rrecibos estão: Ambev, Aracruz, Bradesco, Brasil Telecom, Cemig, Companhia Brasileira de Distribuição (Pão de Açúcar), Copel, Embratel, Embraer, Gerdau, Itaú, Petrobrás, Vale do Rio Doce, Companhia Siderúrgica Nacional, Telebrás, Telesp Celular, Telemig e Unibanco.

O lançamento de ADRs traz vantagens tanto para a empresa quanto para o investidor. Para este, traz a possibilidade de participar do mercado de outro país e, para aquela, uma maior exposição internacional com conseqüente aumento de liquidez de suas ações, além de uma nova fonte de financiamento a baixo custo.

Só pode comprar e vender ADRs os investidores que têm conta no exterior (pessoa física ou jurídica). A abertura da conta é lícita, desde que seja declarada e respeite as regras de tributação. O envio de dinheiro para o exterior só pode ser feito através das instituições financeiras credenciadas a operar câmbio e, se montante ultrapassar US\$ $10 \mathrm{mil}$, o Banco Central deverá ser informado.

Os investidores podem também converter seus ADRs em ações da companhia, e negociá-las no país de origem da companhia. É chamada de operação de arbitragem aquela na qual o investidor percebe distorções entre o preço de um mesmo ativo em dois ambientes de negociação distintos e se beneficia disso. Por exemplo: se o preço das ações de uma empresa (depois de aplicado o fator de conversão para a ADR e depois para dólar) é de US\$20 no Bovespa e de US\$ 21 nos Estados Unidos, há uma oportunidade de comprar aqui, efetuar a conversão e vender lá no mesmo momento, embolsando a diferença. As conversões são feitas pelo banco

\subsubsection{ADR nível I}

O ADR - Nível I é o que tem menor nível de exigências e é negociado no mercado de balcão norte-americano (denominado OTC - Over The Counter). ADRs de Nível I proporcionam aos seus emissores um meio simples e eficiente de formar um grupo de investidores tendo poucos requerimentos legais e relatórios obrigatórios. São negociados no mercado de balcão norte-americano e também em algumas bolsas de valores fora dos Estados Unidos. O estabelecimento de um programa de ADRs Nível I é considerado como o primeiro passo para a entrada no mercado acionário dos Estados Unidos.

Características dos ADRs nível I:

- Negociados no mercado de balcão (fora do mercac organizado);

- $\quad$ Não pode haver oferta pública nos Estados Unidos

- Não precisa atender normas contábeis americanas;

- $\quad$ Não é lançamento de novas ações;

- $\quad$ Ações adquiridas no mercado secundário;

- $\quad$ Tem o objetivo simples de colocar ações no mercado norteamericano, preparando o terreno para futuros lançamentos primários; - $\quad$ É o método mais simples, pois não precisa atender todas as exigências da Securities Exchange Commission - SEC (a CVM norte-americana).

\subsubsection{ADR nível II}

Os ADRs - Nível II são negociados nas bolsas de valores dos EUA (Ex. Nasdaq). Cabe ressaltar que nos níveis I e II não há um lançamento de ações novas. Este nível requer mais demonstrações e relatórios do que no Nível I. A empresa passa a ser obrigada a enviar suas demonstrações contábeis em US GAAP para a SEC, além de outros relatórios. A empresa não pode captar recursos através da emissão de ADRs deste nível e a adesão a este Nível não constitui um IPO. Geralmente as empresas que emitem ADRs neste nível já participam do mercado acionário norte-americano através de ADRs Nível I.

Características dos ADRs nível II:

- $\quad$ Não pode haver oferta pública nos Estados Unidos.

- As demonstrações financeiras devem estar de acordo com os US GAAP

- Deve atender normas contábeis americanas;

- $\quad$ Não é lançamento de novas ações;

- Maiores exigências da SEC, por ser obrigatório o registro do ADR em Bolsa de Valores;

- Há negociação em Bolsa.

\subsubsection{ADR nível III}

O ADR nível III é negociado numa bolsa de âmbito nacional dos Estados Unidos ou na Nasdaq, vinculados a uma oferta pública nos Estados Unidos das ações depositadas. Emitido com base em ações novas emitidas pela companhia. As demonstrações financeiras devem estar de acordo com os US GAAP - United States Generally Accepted Accounting Principles. Portanto, o ADR - Nível III possui o mesmo grau de exigência do ADR - Nível II, contudo há captação de recursos, pois é lastreado em ações novas.

\section{Características dos ADRs nível III:}

- Mais completo e oneroso;

- Deve atender requisitos da SEC e das Bolsas;

- Deve atender normas contábeis americanas;

- Tem como objetivo o levantamento de recursos para a empresa; 
- $\quad$ Atendimento total às exigências da SEC;

- $\quad$ Como o nível II, deve prever um programa de divulgação institucional de alta qualidade.

\subsubsection{Norma 144-A}

Ainda de destaque é o ADR regido pela Norma 144-A, que autoriza uma companhia a negociar suas ações com comunidades de investidores institucionais qualificados, a fim de agilizar a liquidez do mercado de colocações privadas nos Estados Unidos. Além da submissão parcial às exigências da SEC, essa norma representa vantagens por ser forma mais econômica, rápida e fácil de capitação financeira, além da negociação por meio do sistema Portal (private offerings, resales and trading through automated linkage) da Nasdaq. Entretanto, é um meio inacessível às ações que já estejam registradas em bolsas de valores norte-americanas.

\section{$3 \quad$ Resultados}

Os dados utilizados no trabalho são referentes ao período entre primeiro de abril de 2003 e sete de novembro de 2005 , correspondendo a um total de 618 observações diárias para cada ativo e sua respectiva ADR. Os ativos utilizados foram o da Petrobrás (PETR4), da Telemar (TNLP4), da Vale do Rio Doce (VALE5) e do Banco Itaú (ITAU4).

Os dados utilizados podem ser divididos em três variáveis:

- preço de fechamento diário dos ADRs de empresas brasileiras, negociados no mercado norte-americano em dólares (preço efetivo);

- preço de fechamento diário das ações brasileiras, correspondentes aos ADRs, negociadas em reais no mercado brasileiro;

- taxa de câmbio diária, reais (R\$) por dólar (US\$).

Os dados referentes as ADRs foram obtidos na Economática, enquanto os dados das ações brasileiras foram obtidos na página da corretora EasyInvest, e por último, os relacionados a taxa de câmbio diária foram obtidos na página do IPEADATA.

A escolha dessas empresas foi feita devido ao grau importância desses ativos no índice IBOVESPA.

Foram excluídas, para todas as empresas da amostra, as datas que não apresentaram negociações nos dois mercados, por não haver negócios seja com a ação seja com o ADR. Esse fato é dado devido a diferença em datas de feriados brasileiros e americanos.
Foi calculada uma nova variável denominada "preço teórico da ADR" com base no preço do fechamento das ações das empresas, na cotação do dólar e no número de ações correspondentes para cada ADR. Ou seja:

$$
P T_{i t}=\frac{P A_{i t}^{*} N}{C_{t}}
$$

onde: instante t.

$$
\mathrm{PT}_{\mathrm{it}}=\text { Preço teórico da } \mathrm{ADR}_{\mathrm{i}}(\mathrm{US \$}) \text { no }
$$

$\mathrm{PA}_{\mathrm{it}}=$ Preço da Ação $\mathrm{i}_{\mathrm{i}}(\mathrm{R} \$)$ no instante t.

$\mathrm{N}=$ Número de ações correspondentes para cada ADR. no instante t.

$\mathrm{C}_{\mathrm{t}}=$ Cotação de câmbio diária (R\$/US\$)

Esse cálculo possibilita a comparação entre o "preço efetivo da ADR" (PE) com o "preço teórico da ADR"(PT), uma vez que as moedas e quantidades foram igualadas. Com isso pode ser utilizado um teste de comparação de médias incondicionais (Teste T-Student para duas amostras em par para médias). Desprezando os custos de transação, espera-se que as médias incondicionais dessas duas variáveis convirjam para o mesmo ponto. Esse resultado é esperado, pois caso as médias sejam divergentes há um espaço para arbitragem contínua.

O software utilizado para esse estudo foi o SPSS - Statistical Package for the Social Sciences, versão 10.0 .

No primeiro momento estudou-se o grau de dependência linear (Correlação de Pearson) entre as variáveis PE e PT para cada uma das empresas da amostra. Como já esperado, os coeficientes correlação calculados mostram uma alta dependência linear entre as séries, todas as empresas obtiveram uma correlação acima de 99\%. (Tabela 1).

Tabela 1: Correlações do Teste T para duas amostras em par para médias

\begin{tabular}{llll}
\hline Empresa & Observações & Correlação & Sig. \\
\hline Petrobrás & 618 & $99,967 \%$ & 0,000 \\
Telemar & 618 & $99,733 \%$ & 0,000 \\
Vale & 618 & $99,973 \%$ & 0,000 \\
Itaú & 618 & $99,971 \%$ & 0,000 \\
\hline
\end{tabular}


Apesar da alta correlação, não se pode afirmar que não existam possibilidades de arbitragem entre esses mercados. Pode se concluir que se existe essa oportunidade, não é tão comum aparecer uma chance.

Após essa verificação optou-se por trabalhar com uma única variável para cada empresa, expressa através da razão entre PE e PT. Ou seja:

$$
R_{i t}=\frac{P E_{i t}}{P T_{i t}}
$$

Onde:

$\mathrm{PE}_{\mathrm{it}}=$ Preço Efetivo da $\mathrm{ADR}_{\mathrm{i}}$ no instante $\mathrm{t}$ $\mathrm{PT}_{\mathrm{it}}=$ Preço Teórico da $\mathrm{ADR}_{\mathrm{i}}$ no instante $\mathrm{t}$

Com essa variável é possível verificar a diferença percentual entre o preço teórico e o preço efetivo da ADR da i-ésima empresa.

Em caso de um mercado eficiente (despresando os custos de transação) essa variável essa variável deveria ser igual a um, fato que não se verifica. Portanto quando essa variável é superior a um, existe uma janela de oportunidade, que pode ser aproveitada comprando ações no mercado local e vender ADRs no mercado Norte americano. Quando essa razão for inferior a um, a arbitragem é dada a partir da compra de ADRs no mercado dos Estados Unidos e a venda das ações correspondentes a essa ADR no mercado brasileiro.

Para testar estatisticamente se a média incondicional dessa razão é igual a um, aplicou-se o teste T-Student para uma amostra (Tabela 2). Esse teste indica possibilidades de arbitragem freqüentes para as empresas Telemar e Vale do Rio Doce, pois o teste $\mathrm{T}$ rejeitou (nível de 5\%) a hipótese que a média dessa razão seja igual a um. Já para as empresas Petrobrás e Itaú, não se pode dizer o mesmo, uma vez que a hipótese testada pode ser aceita (nível de 5\%).

Tabela 2: Teste $\mathbf{T}$ para uma amostra (OneSample)

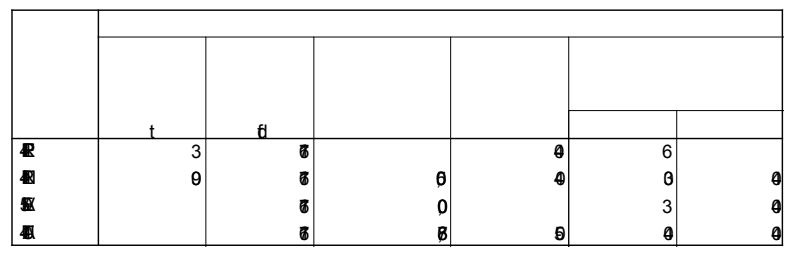

Como esse teste é utilizado para testar a média incondicional da série de dados, ele somente consegue indicar os ativos que possuem freqüentemente oportunidades de arbitragem. Contudo as possibilidades de arbitragem podem aparecer em algumas janelas, que não são constantes. Para verificar isso a Tabela 3 mostra as estatísticas descritivas das séries referentes a variável razão de todas as empresas utilizadas.

Pode ser observado (Tabela 3) que a série dessa variável para a Petrobrás possui um mínimo de 0,96 , o que indica uma distancia de $4 \%$ em dos preços teóricos e efetivos da ADR, apesar de ter uma média incondicional estatisticamente igual a um, esse instante pode apresentar possibilidades de arbitragem, ou seja, podem existir janelas de arbitragem. O mesmo pode ser dito para a empresa Itaú, porém a diferença entre preços máxima chegou a $3 \%$.

\section{Tabela 3: Estatísticas descritivas}

\begin{tabular}{|c|c|c|c|c|c|}
\hline & $\mathrm{N}$ & & & & \\
\hline $\mathbb{P}$ & 6 & $\theta$ & & 5 & \\
\hline ๘ & 6 & 9 & 0 & 2 & \\
\hline$\underline{w}$ & 6 & 9 & & 8 & 2 \\
\hline 盾 & 6 & $g$ & & & $B$ \\
\hline W & 6 & & & & \\
\hline
\end{tabular}

Na tentativa de prever a abertura de janelas de arbitragem, estudou se a autocorrelação (ACF) e autocorrelação parcial (PACF) das séries, e com isso verificar se as médias condicionais das séries são constantes. Além disso, aplicou-se o teste Ljung-Box no intuito de verificar se a autocorrelação é estatisticamente significativa.

A variável estudada em relação a empresa Petrobrás apresenta ACF e PACF significativas ( Figura 1 e Figura 2, respectivamente) para a primeira defasagem. Para as empresas Telemar e Itaú não existe dependência linear significativa estatisticamente para nenhuma defasagem (Figura 3, Figura 4, Figura 7 e Figura 8). A série da variável referente a empresa Vale do Rio Doce também possui ACF e PACF significativas (Figura 5 e Figura 6), o que indica certa previsibilidade utilizando os modelos ARIMA.

$\mathrm{O}$ teste de Ljung-Box indicou (utilizando um nível de significância de 5\%) que as séries da Petrobrás e Vale do Rio Doce possuem dependência linear significativa, com isso esses dados podem ser modelados por modelos ARIMA. 


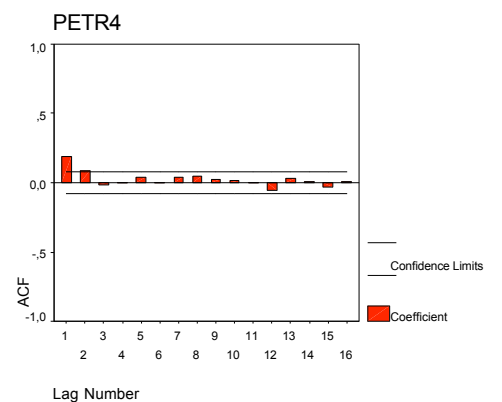

Figura 1: Autocorrelação PETR4

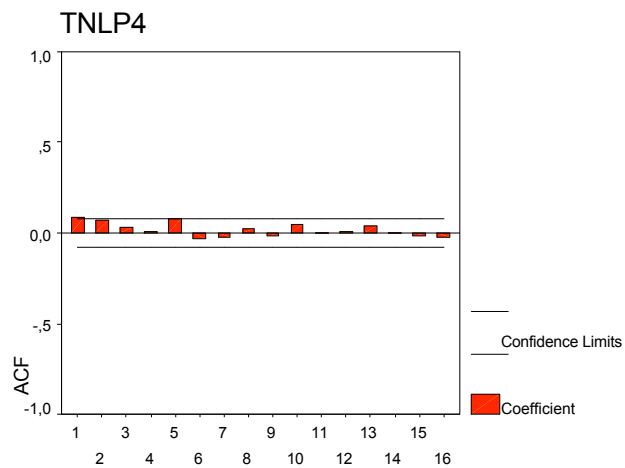

Lag Number

Figura 3: Autocorrelação TNLP4

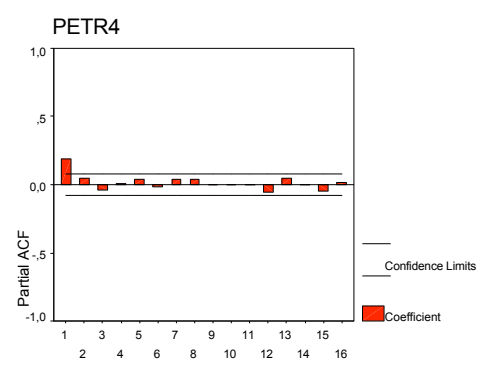

Lag Number

Figura 2: Autocorrelação Parcial PETR4

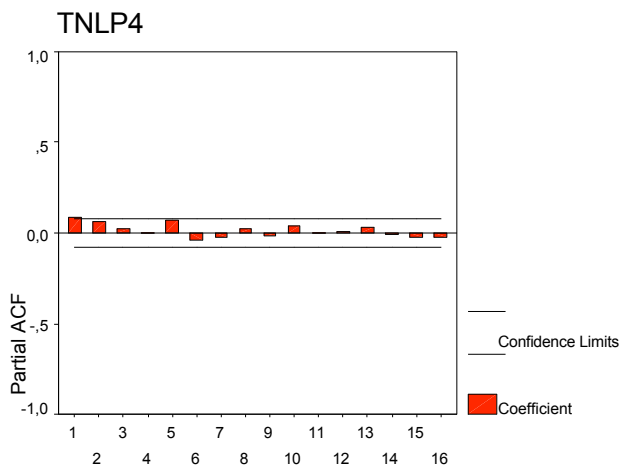

Lag Number

Figura 4: Autocorrelação Parcial TNLP4 


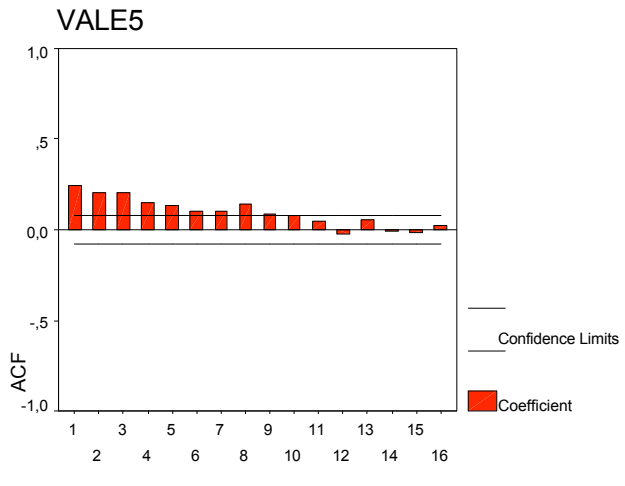

Lag Number

Figura 5: Autocorrelação VALE5

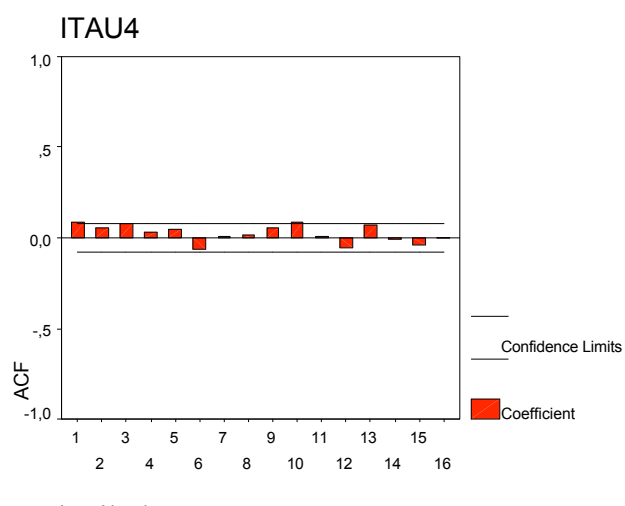

Lag Number

Figura 7: Autocorrelação ITAU4

O modelo ARIMA melhor ajustado para a série da Petrobrás é o AR(1), cujo coeficiente estimado é de 0,2858 e a constante é de 0,9988 . Já para a série da Vale do Rio Doce é o ARMA $(1,1)$ com coeficiente autorregressivo (AR) de 0,9510, coeficiente de média móvel (MA) de 0,7555 e constante de 0,9980 .

Esses modelos possibilitam a prever o resultado da razão entre preço efetivo e preço teórico das ADRs, e com isso auxilia a tomada de decisão de quando fazer a operação e quando disponibilizar recursos para efetivar a mesma. Com as janelas de oportunidades modeladas o investidor poderá prever quando o mercado ira se ajustar fechando a janela de arbitragem.

\section{Conclusões}

O estudo de caso reflete a assimetria de informação que existe entre o mercado brasileiro e o mercado norte americano. Essa assimetria de informação em muitos casos é corrigida através de arbitragem, ou seja, investidores atentos com as janelas oportunidades alteram a oferta e demanda, ajustando o preço para o preço justo.

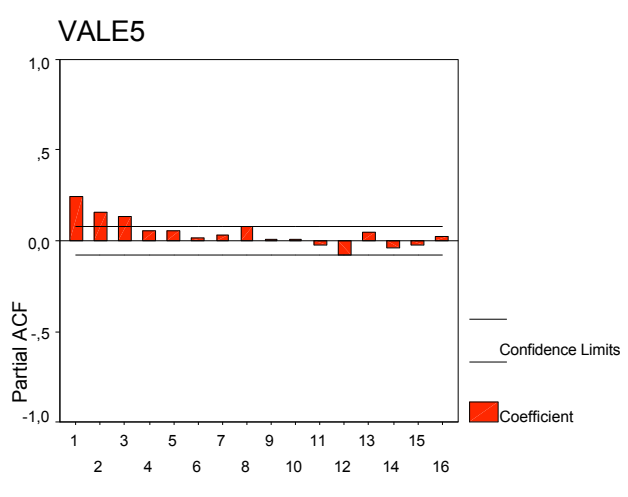

Lag Number

Figura 6: Autocorrelação Parcial VALE5

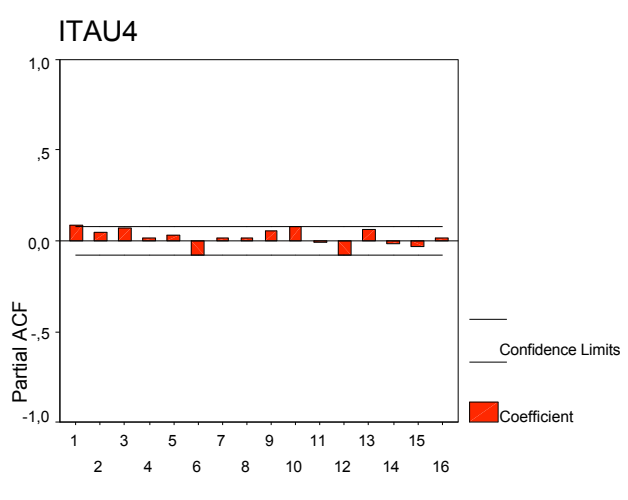

Lag Number

Figura 8: Autocorrelação Parcial ITAU4

$\mathrm{O}$ teste T-Student para as médias detectou que em duas, das quatro empresas testadas, a razão entre o preço teórico e o preço efetivo é diferente de um. Esse resultado sugere que existe oportunidades freqüentes de arbitragem utilizando as ADRs dessas empresas. Já para as outras duas empresas, foi detectado uma diferença de $3 \%$ e $4 \%$, o que indica que, apesar das oportunidades de arbitragem não serem freqüentes, podem aparecer algumas janelas de oportunidades.

Analisando a dependência linear temporal das séries, através dos gráficos de ACF e PACF e do teste de Ljung-Box, verificou-se em duas empresas a possibilidade de previsão da razão entre o preço efetivo e o teórico das ADRs, e com isso modelos ARIMA foram estimados para modelar o comportamento temporal dessa série, podendo utilizar esses resultados para decidir a hora de fazer a operação, minimizando assim riscos como o de liquidez dos papeis.

Esse artigo apresenta um estudo acadêmico, o que devido a algumas simplificações, não pode ser aplicado diretamente, há necessidades de algumas alterações. Uma limitação é a não utilização das taxas de transação, o que pode inviabilizar as operações de arbitragem. Portanto um estudo mais complexo envolvendo todas as taxas de transação pode ser elaborado no futuro para efeitos práticos e acadêmicos. 


\section{Referências}

[1] CAMARgos, M. A., GOMES, G. D. e BARBOSA, F. V. Integração de Mercados e Arbitragem com Títulos Transfronteiriços: ADRS American Depositary Receipts. Caderno de Pesquisas em Administração, São Paulo, 10, 5167,2003.

[2] CAMPBELL, J. Y., and SHILLER, R. (1988). Stock prices, earnings and expected dividends. Journal of Finance, 43, 661-676, 1988.

[3] FAMA, E. F. (1991). Efficient capital markets II. The Journal of Finance, Chicago: American Finance Association, 46, 1575-1617, 1991.

[4] ____and FRENCH, KENNETH R.: Permanent and temporary components of stock prices. Journal of Political Economy, 96, 246-73, 1988.

[5] ____Efficient capital markets: a review of theory and empirical work. The Journal of Finance, 25, 383-417, 1970.

[6] [7] FRIEDMAN, M.: The methodology of positive economics, Essays in Positive Economics. Chicago: University of Chicago Press, 3-43 1953.

[7] RODRIGUES, E. L.: Segmentação, fragmentação e composição de ordens no mercado de capitais brasileiro: os efeitos da listagem de ações de empresas brasileiras no mercado norte americano através do mecanismo de recibos de depósito de ações. Tese (Doutorado em Administração) Instituto de Pós-Graduação e Pesquisa em Administração. Rio de Janeiro: UFRJ, 1999. 